\title{
Ferulsinaic Acid Modulates SOD, GSH, and Antioxidant Enzymes in Diabetic Kidney
}

\author{
Ahmed Amir Radwan Sayed ${ }^{1,2}$ \\ ${ }^{1}$ Biochemistry Department, Faculty of Science, King Abdulaziz University, P.O. Box 80203, Jeddah 21589, Saudi Arabia \\ ${ }^{2}$ Chemistry Department, Faculty of Science, Minia University, El-Minia 61519, Egypt
}

Correspondence should be addressed to Ahmed Amir Radwan Sayed, sayedaar1@yahoo.com

Received 28 January 2012; Revised 9 May 2012; Accepted 10 May 2012

Academic Editor: Debprasad Chattopadhyay

Copyright (C) 2012 Ahmed Amir Radwan Sayed. This is an open access article distributed under the Creative Commons Attribution License, which permits unrestricted use, distribution, and reproduction in any medium, provided the original work is properly cited.

\begin{abstract}
The efficacy of Ferulsinaic acid (FA) to modulate the antioxidant enzymes and to reduce oxidative stress induced-diabetic nephropathy (DN) was studied. Rats were fed diets enriched with sucrose (50\%, wt/wt), lard (30\%, wt/wt), and cholesterol $(2.5 \%, \mathrm{wt} / \mathrm{wt})$ for 8 weeks to induce insulin resistance. After a DN model was induced by streptozotocin; $5,50 \mathrm{and} 500 \mathrm{mg} / \mathrm{kg}$ of FA were administrated by oral intragastric intubation for 12 weeks. In FA-treated diabetic rats, glucose, kidney/body weight ratio, creatinine, BUN, albuminurea, and creatinine clearance were significantly decreased compared with non treated diabetic rats. Diabetic rats showed decreased activities of SOD and GSH; increased concentrations of malondialdehyde and IL-6 in the serum and kidney, and increased levels of 8-hydroxy-2'-deoxyguanosine in urine and renal cortex. FA-treatment restored the altered parameters in a dose-dependent manner. The ultra morphologic abnormalities in the kidney of diabetic rats were markedly ameliorated by FA treatment. Furthermore, FA acid was found to attenuate chronic inflammation induced by both Carrageenan and dextran in rats. We conclude that FA confers protection against injuries in the kidneys of diabetic rats by increasing activities of antioxidant enzymes and inhibiting accumulation of oxidized DNA in the kidney, suggesting a potential drug for the prevention and therapy of DN.
\end{abstract}

\section{Introduction}

Diabetes mellitus (DM) is a life-threatening metabolic disorder and the disease is becoming a serious social problem. Hyperglycemia is the major cause of diabetic complications, such as retinopathy, nephropathy, and neuropathy $[1,2]$.

Diabetic nephropathy (DN) is characterized by structural abnormalities including hypertrophy of both glomerular and tubular elements, increase in the thickness of glomerular basement membranes, and progressive accumulation of extracellular matrix components [3]. It also results in functional alterations including the early increase in the glomerular filtration rate with intraglomerular hypertension, subsequent proteinuria, systemic hypertension, and eventual loss of renal function [3]. The development of irreversible renal change in diabetes mellitus such as glomerulosclerosis and tubulointerstitial fibrosis results ultimately in end stage renal disease [1]. Although adequate control of blood glucose levels may prevent the development of complications, it is difficult to achieve strict blood glucose control, leading to a year-by-year increase in the number of patients with diabetes [4].

Although the mechanism of DN has not yet been clarified because of the complexity of the pathophysiology of DM, numerous factors have been reported to be involved, including the activation of the renin-angiotensin system [5], activation of protein kinase $C \beta$ [6], activation of nuclear factor kaba B (NF- $\kappa$ B) [7], enhanced formation of advanced glycation end products (AGEs) [8], and acceleration of oxidative stress [9]. Many experimental evidences suggest the involvement of free radicals in the pathogenesis of diabetes [10] and more importantly in the development of diabetic complications [11]. Free radicals are capable of damaging cellular molecules, DNA, proteins, and lipids leading to altered cellular functions. Many recent studies reveal that antioxidants capable of neutralizing free radicals are effective in preventing experimentally induced diabetes in animal models $[12,13]$ as well as reducing the severity 
of diabetic complications [11]. Ferulic acid, an antioxidant of plant cell wall, was reported to prevent functional and pathological abnormalities in the kidney of diabetic rats reducing oxidative stress and inflammation $[14,15]$.

Many plants synthesize an array of chemical compounds that are not involved in their primary metabolism. These "secondary compounds" instead of serving a variety of ecological functions, they ultimately enhance the plant's survival during stress. In addition, these compounds may be responsible for the beneficial effects of fruits, vegetables, and many plants on an array of health-related measures. Traditional herbal medicines have been employed for thousands of years and have contributed greatly to the prevention and treatment of various diseases, including diabetes. They are still valuable for human health and have received much attention as potential sources of new therapeutic agents due to their varied biological activity and low toxicity [16]. Ferula sinaica $L$. (Apiaceae) has some 130 species distributed throughout the Mediterranean area and central Asia. These plants are used in Egypt as spices and in the preparation of local drugs. The resins are reported to be used for stomach disorders such as a febrifuge and carminative agent and in the treatment of skin infections and hysteria [17]. Previous work showed that the main constituents of this genus are sesquiterpenes and sesquiterpene coumarins [18]. Ferulsinaic acid (FA) is the first member of a new rearranged class of sesquiterpene coumarins from the genus Ferula. It was isolated from F. sinaica $L$. The molecular formula of FA is found to be $\mathrm{C}_{24} \mathrm{H}_{30} \mathrm{O}_{5}$. The structure of $\mathrm{FA}$ was established in a previous work of our research group [19] as indicated below in Scheme 1.

Extracts of $F$. sinaica was found to inhibit the spontaneous movements of rabbit jejunum and guinea pig ileum and acetylcholine induced contractions. Extracts also inhibited the contractions of rabbit tracheal smooth muscle induced by acetylcholine stimulation and the contractions of guinea pig tracheal smooth muscle induced by histamine stimulation. In addition, the extract inhibited the contractions of rabbit aorta induced by norepinephrine stimulation [20]. Furthermore, extracts of $F$. sinaica inhibited the spontaneous movements of rat and guinea pig uterine smooth muscle and also the contractions induced by oxytocin stimulation and have some antioxytocic potential [21].

FA was found to extend life span of wildtype Caenorhabditis elegans (C. elegans) under standard condition. Moreover, resistance to both heat stress and induced chemical stress of C. elegans were improved. Furthermore, FA was found to attenuate the formation reactive oxygen species (ROS) and advanced glycation end products (AGEs) in C. elegans [22].

In the present study, the antioxidant power as well as the anti-inflammatory effect of FA were examined to evaluate its efficacy to attenuate ROS production, inflammation, and to modulate the antioxidant enzymes of diabetic kidney in rats.

\section{Materials and Methods}

2.1. Animals. Adult male Albino rats weighing 180 to $200 \mathrm{~g}$ were used throughout this study. The animals were housed in

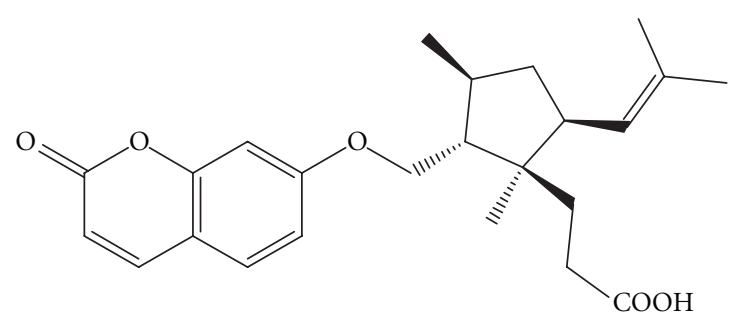

SCHEME 1

cages and received normal rat chow and tap water ad libitum in a constant environment (room temperature $28 \pm 2^{\circ} \mathrm{C}$, room humidity $60 \pm 5 \%$ ) with a $12 \mathrm{~h}$ light and $12 \mathrm{~h}$ dark cycle. The animals were kept under observation for one week prior to the start of the experiments.

2.2. Isolation and Purification of FA. Air-dried roots of F. sinaica were collected from North Sinai Peninsula, ElArish, Egypt. $15 \mathrm{~kg}$ of $F$. sinaica were ground and extracted with $\mathrm{CH}_{2} \mathrm{Cl}_{2}$ at room temperature. The extract was concentrated to obtain a residue of $1100 \mathrm{~g}$. The residue was fractionated by silica gel CC $(6 \cdot 120 \mathrm{~cm})$ eluted with hexane, followed by gradient elution with hexane- $\mathrm{CH}_{2} \mathrm{Cl}_{2}$ up to $100 \% \mathrm{CH}_{2} \mathrm{Cl}_{2}$ and finally with $\mathrm{CH}_{2} \mathrm{Cl}_{2}-\mathrm{MeOH}(85: 15)$. The hexane- $-\mathrm{CH}_{2} \mathrm{Cl}_{2}$ extract $(1: 3,140 \mathrm{~g})$ was purified by HPLC $\left(\mathrm{MeOH}-\mathrm{H}_{2} \mathrm{O}, 73: 27\right)$ to afford FA (100 mg) [19].

2.3. Induction of DN Model and Study Design. Seventy rats were used in this experiment. Rats were fed diets enriched with sucrose $(50 \%, \mathrm{wt} / \mathrm{wt})$, lard $(30 \%$, wt/wt), and cholesterol $(2.5 \%, \mathrm{wt} / \mathrm{wt})$ for 8 weeks to induce insulin resistance. Ten rats were used as control group (group $1, n=10$ ), which received a single tail vein injection of $0.1 \mathrm{~mol} / \mathrm{L}$ citrate buffer only. A group of 60 rats were intravenously injected with STZ (65 mg/kg body weight), which was freshly prepared in a $0.1 \mathrm{~mol} / \mathrm{L}$ citrate buffer ( $\mathrm{pH} 4.5)$, after fasting for 12 hours. Only rats with blood glucose higher than $200 \mathrm{mg} / \mathrm{dL}$ after 5 days will be considered as being diabetic in the fasting state, by using One Touch select analyzer (Life Scan, Inc., UK). Rats with blood glucose lower than $200 \mathrm{mg} / \mathrm{dL}$ were excluded from the study. All studies were carried out one week after STZ had been injected. Fifty diabetic rats were randomly divided into 5 groups: $\mathrm{DN}$, diabetic and treated with metformin- $\mathrm{HCl}$ (MF) $\left(125 \mathrm{mg} \mathrm{kg}^{-1} \mathrm{~d}^{-1}\right.$; DN + MF) [23], diabetic and treated with a low dose $\left(5 \mathrm{ng} \mathrm{kg}^{-1} \mathrm{~d}^{-1}\right)$ of FA (DN + FA1), diabetic and treated with a medium dose $\left(50 \mathrm{ng} \mathrm{kg}^{-1} \mathrm{~d}^{-1}\right)$ of FA (DN+FA2), and diabetic and treated with a high dose $\left(500 \mathrm{ng} \mathrm{kg}^{-1} \mathrm{~d}^{-1}\right)$ of FA (DN + FA3). The $\mathrm{LD}_{50}$ of FA was found to be $2 \mu \mathrm{g} / \mathrm{kg}$. The MF and FA were administered with distilled water via intragastric intubation. Treatments were continued for 12 weeks. Body weight and blood glucose levels were measured regularly. At the end of the experiment, animals were sacrificed using ether anaesthesia. Kidneys were dissected and rinsed with cold PBS and then weighed. An index of renal hypertrophy was estimated by comparing the wet weight of the left kidney to the body weight. 
2.4. Kidney Homogenate Preparation. Every kidney tissue was cut into small pieces and washed by phosphate-buffered saline. Furthermore, it was grinded in a homogenization buffer $\{0.05 \mathrm{M}$ Tris- $\mathrm{HCl} \mathrm{pH} 7.9,25 \%$ glycerol, $0.1 \mathrm{mM}$ EDTA, and $\left.0.32 \mathrm{M}\left(\mathrm{NH}_{4}\right)_{2} \mathrm{SO}_{4}\right\}$ containing a protease inhibitor tablet (Roche, Germany). The lysates were homogenized on ice using a Polytron homogenizer. The solution has been sonicated in an ice bath to prevent overheating for 15 seconds followed by centrifugation at $12000 \mathrm{rpm}, 4^{\circ} \mathrm{C}$ for 5 minutes. The supernatant was aliquoted and stored at $-80^{\circ} \mathrm{C}$ and assayed for protein concentration using BCA kit (Pierce, Rockford, USA) using albumin diluted in a lysis buffer as a standard. The homogenate was used for the determination of reduced glutathione (GSH), level of lipid peroxidation (MDA), concentration of $N \varepsilon$-carboxymethyl lysine (CML), activity of superoxide dismutase (SOD), and level of IL-6. The other kidneys from each group were used for histopathological examination, determination of the level of AGEs, and for isolation of renal DNA.

2.5. Blood Sampling and Analysis. Blood samples of rats were centrifuged at $2,000 \mathrm{~g}$ for 10 minutes at $4^{\circ} \mathrm{C}$, and aliquoted for the respective analytical determinations. The diagnostic kits for determinations for plasma levels of glucose, creatinine $(\mathrm{Cr})$, blood urea nitrogen (BUN), sodium, and potassium were purchased from BioSystem (Barcelona, Spain). All analyses were performed in accordance with the manuals provided by the manufacturer.

2.6. Analysis of Urine Parameters. Urine samples were collected by placing the rats in individual metabolic cages for $24 \mathrm{~h}$ before diabetes had been induced and the day before the end of treatment. The urine albumin concentration was determined with an ELISA kit (Nephrat II, Exocell, Philadelphia, PA, USA) and the concentration of $\mathrm{Cr}$ in pooled urine samples was determined by the commercial assay kit. All analyses were performed in accordance with the manuals provided by the manufacturers. The $24 \mathrm{~h}$ urinary albumin excretion rate (UAER) was calculated as UAER ( $\mu \mathrm{g}$ $24 \mathrm{~h}-1)=$ urinary albumin $\left(\mu \mathrm{g} \mathrm{mL}^{-1}\right) \times 24 \mathrm{~h}$ urine volume $(\mathrm{mL})$. Cr clearance (Ccr) was calculated using the following equation: $\operatorname{Ccr}\left(\mathrm{mL} \mathrm{min}^{-1} \mathrm{~kg}^{-1}\right)=\left(\right.$ urinary $\operatorname{Cr}\left(\mathrm{mg} \mathrm{dL}^{-1}\right) \times$ urinary volume $(\mathrm{mL})$ /serum $\left.\mathrm{Cr}\left(\mathrm{mg} \mathrm{dL}^{-1}\right)\right) \times(1000 /$ body weight $(\mathrm{g})) \times(1 / 1440(\mathrm{~min}))[24]$.

2.7. Determining Enzymatic Activities. The activities of total SOD (EC: 1.15.1.1) as well as the concentrations of MDA and GSH in the kidney homogenate were determined using commercially available kits from BioVision Research Products (Linda Vista Avenue, USA) according to the methods described by Nishikimi et al., and Sayed [25, 26]; Ohkawa et al. and Mekheimer et al. [27, 28], and Moron et al. [29], respectively.

2.8. Determination of IL-6. IL-6 concentration in the serum and in the kidney homogenate was determined by an ELISA kit. The ELISA for determination of IL-6 was performed using a commercially available kit from R\&D (Mannheim, Germany) according to the instructions of the manufacturer.
2.9. Measurement of Urinary and Renal 8-Hydroxy-2'deoxyguanosine. Urinary 8-hydroxy-2'-deoxyguanosine (8$\mathrm{OHdG}$ ) levels were determined using an enzyme-linked immunosorbent assay kit from Genox Corporation (Baltimore, MD. USA) according to the method of Matsubasa et al. [30] and corrected by using individual urine creatinine concentrations. Extraction of renal DNA was performed using a DNA extraction kit (Promega, Germany) following the manufacturer's protocol. The genomic DNA samples from kidney tissue were also used for the determination of 8-OHdG using the competitive ELISA kit.

2.10. Renal AGEs Level. The renal AGE level was determined according to a previous method with slight modifications [31, 32]. Minced kidney tissue was delipidated with chloroform and methanol $(2: 1, \mathrm{v} / \mathrm{v})$ overnight. After washing, the tissue was homogenized in $0.1 \mathrm{~N} \mathrm{NaOH}$, followed by centrifugation at $8,000 \mathrm{~g}$ for $15 \mathrm{~min}$ at $4^{\circ} \mathrm{C}$. The amounts of AGEs in these alkali-soluble samples were determined by measuring the fluorescence at an emission wavelength of $440 \mathrm{~nm}$ and an excitation wavelength of $370 \mathrm{~nm}$ using a fluorescence spectrophotometer (Hitachi, Japan). A native bovine serum albumin (BSA) preparation $\left(1 \mathrm{mg} \mathrm{mL}^{-1}\right.$ of $0.1 \mathrm{~N} \mathrm{NaOH}$ ) was used as a standard. The fluorescence values of samples were measured at a protein concentration of $1 \mathrm{mg} \mathrm{mL}^{-1}$ and expressed in AU compared with a native BSA preparation.

2.11. Assessment of Renal CML. The supernatant of the kidney homogenate was tested for CML using the anti-CML rat autoantibody ELISA kit which employs the semiquantitative enzyme immunoassay technique. The absorbance of the resulting yellow product is measured at $450 \mathrm{~nm}$ [33].

2.12. Histopathological Examination. Renal tissues were collected after animal sacrifice, fixed in 10\% formalin, processed routinely, and embedded in paraffin. 5- $\mu \mathrm{m}$ thick sections were prepared and stained with periodic acid Schiff (PAS). Glomerular histopathological changes and mesangial lesions were scored in term of the glomerular mesangial expansion (increase in the mesangial matrix) [34].

In order to evaluate the anti-inflammatory activity of FA on the acute inflammation, carrageenan-induced rat paw edema and dextran-induced rat paw edema were estimated as described by Arunachalam et al. [35] with slight modification.

2.13. Carrageenan-Induced Rat Paw Edema. Thirty rats were divided into 5 groups, each 6 rats. FA at 5, 50, and $500 \mathrm{ng} / \mathrm{kg}$ and indomethacin at $10 \mathrm{mg} / \mathrm{kg}$ body weight in olive oil were given to rats orally $30 \mathrm{~min}$ before carrageenan injection. The same volume of the vehicle was given to control group. The left rear plantar region of the rats was injected with $0.1 \mathrm{~mL}$ of carrageenan ( $1 \%$ in saline). The edema produced was determined by measuring the difference of the paw diameter using an analogic pakimeter (vernier) before carrageenan injection and at 0,3 , and $5 \mathrm{~h}$ after carrageenan injection. 
2.14. Dextran-Induced Rat Paw Edema. The paw edema was induced in the right hind paw by subplantar injection of $0.1 \mathrm{~mL}$ of freshly prepared $1 \%$ dextran solution. Paw thickness was measured at 0,45 , and 90 min after dextran injection. The rats were treated as above. The percentage of inhibition was calculated.

2.15. Statistical Analysis. All group values are expressed as the mean \pm SD. Data was evaluated using the Sigma Stat (version 13.0) statistical analysis program (by using SPSS 11.09 for windows). An analysis of variance test was performed initially to test differences in the treatment. After the analyses of variance, a Tukey post-hoc test was performed to examine whether there were any significant differences between different treatment groups, the level of significance was set at $P<0.05$.

\section{Results}

3.1. Effects of FA Treatment on Blood Glucose and Kidney/Body Weight Ratio. Data in Table 1 showed that the STZ injection resulted in a nearly 5-fold increase of the fasting blood glucose levels in the Albino rats. At the end of the 12-week period, the final kidney/body weight ratios of untreated diabetic animals were significantly higher than those of control animals $(P<0.05)$. FA-treated diabetic animals showed a significant reduction of this kidney/body weight ratio, which approached the levels of the MF group compared with the diabetic animals $(P<0.05)$. Moreover, there was also a significant correlation $(P<0.05)$ between the dosage groups.

3.2. Effects of FA Treatment on Renal Function. Table 1 shows that the BUN, creatinine, 24-hour Upro, sodium, potassium, and Ccr levels were significantly higher in the DN group than in the normal control group $(P<0.05)$. The low dose of FA markedly reduced Upro, potassium, and Ccr in the DN group but did not reduce serum BUN and Scr. The medium and high doses of FA significantly reduced all previously listed renal functional parameters in the DN rats $(P<0.05)$.

\subsection{Effects of FA Treatment on Activities of Antioxidant} Enzymes and Oxidative Stress Markers. The activity of SOD and concentration of GSH were lower, whereas concentration of MDA was higher in the kidney homogenate of the DN group than the control group $(P<0.05)$, suggesting that these rats suffered from oxidative stress (Table 2 ). Treatment with medium and high doses of FA significantly decreased the concentrations of MDA and significantly increased SOD activity and GSH concentrations $(P<0.05)$. These results indicate that FA ameliorates oxidative stress in $\mathrm{DN}$ rats. Metformin $\mathrm{HCl}$ significantly increased the antioxidant enzymes activities $(P<0.05)$.

3.4. Effects of FA Treatment on Serum and Renal IL-6. Diabetes significantly increases the degree of inflammation and the release of IL- 6 in DN group compared with the normal control group $(P<0.05)$. Treatment of animals with FA and metformin appreciably attenuated this inflammation

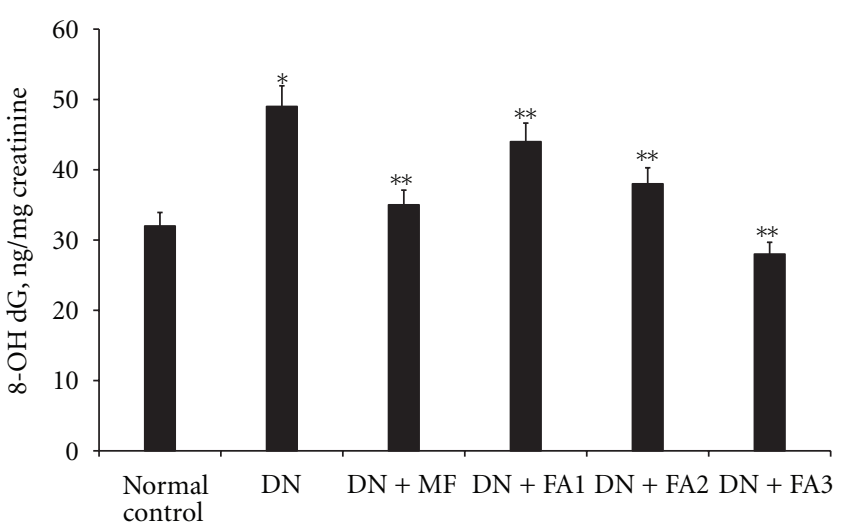

(a)

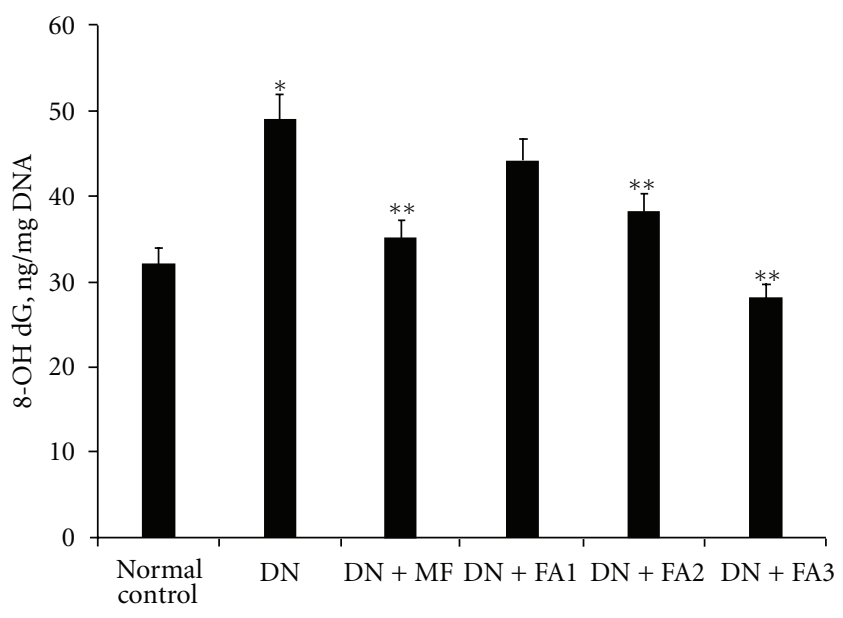

(b)

Figure 1: 8-Hydroxy-2'-deoxyguanosine levels in the urine (a) and renal cortex (b) of rats. Urinary and renal cortex 8-OHdG levels in diabetic rats were significantly attenuated in a dose-dependent manner after FA administration. Data are expressed as the means \pm SD. DN indicates diabetes untreated group; FA1, FA2, and FA3, diabetic rats treated with low dose $(5 \mathrm{ng} / \mathrm{kg})$ of FA (DN + FA1), middle dose $(50 \mathrm{ng} / \mathrm{kg})$ of FA (DN + FA2), and high dose $(500 \mathrm{ng} / \mathrm{kg})$ of FA $(\mathrm{DN}+\mathrm{FA} 3)$, respectively. ${ }^{*} P<0.05$ versus normal control group, ${ }^{* *} P<0.05$ versus diabetes untreated group.

and IL-6 production in all treated groups compared with DN group $(P<0.05)$, Tables 1 and 2 .

3.5. Effects of FA on the Renal AGEs and CML. As a result of diabetes the renal levels of AGEs and CML were significantly elevated in the STZ-diabetic rats. These elevated levels were effectively lowered in a dose-dependent manner by FA treatment for 12 weeks (Table 2).

3.6. Effects of FA Treatment on Urinary and Renal 8-OHdG. The total amounts of urinary $8-\mathrm{OHdG}$ excretion were significantly greater in STZ-induced diabetic rats than in control rats at 12 weeks after the onset of diabetes $(P<0.05)$. Administration of FA suppressed the increase in urinary excretion of 8-OHdG in the diabetic rats to the same extent as $\mathrm{MF}(P<0.05)$. In parallel with the urine results, the 
TABLe 1: Physiological, biochemical, and renal functional parameters of the rats.

\begin{tabular}{|c|c|c|c|c|c|c|}
\hline & Normal control & $\mathrm{DN}$ & $\mathrm{DN}+\mathrm{MF}$ & $\mathrm{DN}+\mathrm{FA} 1$ & $\mathrm{DN}+\mathrm{FA} 2$ & $\mathrm{DN}+\mathrm{FA} 3$ \\
\hline Initial body weight, $g$ & $190.3 \pm 9.5$ & $192.4 \pm 8$ & $191.5 \pm 7.4$ & $190.9 \pm 7$ & $193 \pm 9.2$ & $191.3 \pm 6.9$ \\
\hline Final body weight, $g$ & $265.5 \pm 8.1$ & $163.9 \pm 9.2^{\mathrm{a}}$ & $206.3 \pm 8.5^{\mathrm{a}, \mathrm{b}}$ & $201.3 \pm 17.5^{\mathrm{a}, \mathrm{b}}$ & $211.2 \pm 8.9^{\mathrm{a}, \mathrm{b}}$ & $212 \pm 11.3^{\mathrm{a}, \mathrm{b}}$ \\
\hline Glucose, $\mathrm{mmol} / \mathrm{L}$ & $4.98 \pm 0.48$ & $16.15 \pm 1.55^{\mathrm{a}}$ & $6.2 \pm 1.59^{\mathrm{a}, \mathrm{b}, \mathrm{d}}$ & $8.2 \pm 1.5^{\mathrm{a}, \mathrm{b}, \mathrm{d}}$ & $7.81 \pm 1.3$ & $7.31 \pm 0.59^{\mathrm{a}, \mathrm{b}, \mathrm{c}}$ \\
\hline Kidney/body weight, $g / g, \times 10^{-3}$ & $6.29 \pm 0.35$ & $11.2 \pm 1.52^{\mathrm{a}}$ & $8.1 \pm 1.2^{\mathrm{a}, \mathrm{b}}$ & $8.5 \pm 1.31^{\mathrm{a}, \mathrm{b}, \mathrm{d}}$ & $7.9 \pm 1.39^{\mathrm{a}, \mathrm{b}}$ & $7.5 \pm 1.5^{\mathrm{a}, \mathrm{b}, \mathrm{c}}$ \\
\hline $\mathrm{BUN}, \mathrm{mmol} / \mathrm{L}$ & $6.81 \pm 1.3$ & $12.35 \pm 3.1^{\mathrm{a}}$ & $9.59 \pm 1.65^{\mathrm{a}, \mathrm{b}}$ & $11.34 \pm 1.35^{\mathrm{a}, \mathrm{d}}$ & $9.2 \pm 1.1^{\mathrm{a}, \mathrm{b}, \mathrm{c}}$ & $8.55 \pm 1.29^{\mathrm{a}, \mathrm{b}, \mathrm{c}}$ \\
\hline Serum creatinine, $\mathrm{mmol} / \mathrm{L}$ & $50.6 \pm 7.1$ & $65.12 \pm 8.7^{\mathrm{a}}$ & $57.9 \pm 6.5^{\mathrm{a}}$ & $62.1 \pm 5.9^{\mathrm{a}, \mathrm{d}}$ & $54.3 \pm 3.4^{\mathrm{a}, \mathrm{b}, \mathrm{c}}$ & $52.16 \pm 6.8^{\mathrm{a}, \mathrm{b}, \mathrm{c}}$ \\
\hline Ccr $\mathrm{mL} \min ^{-1} \mathrm{~kg}^{-1}$ & $3.39 \pm 0.4$ & $6.39 \pm 0.6^{\mathrm{a}}$ & $4.52 \pm 0.35^{\mathrm{a}, \mathrm{b}}$ & $4.45 \pm 0.41^{\mathrm{a}, \mathrm{b}}$ & $3.98 \pm 0.51^{\mathrm{b}}$ & $3.75 \pm 0.46^{\mathrm{b}}$ \\
\hline $\mathrm{U}$ prot, $\mathrm{mg} / 24 \mathrm{~h}$ & $8 \pm 1.1$ & $23.6 \pm 2.5^{\mathrm{a}}$ & $16.8 \pm 2.5^{\mathrm{a}, \mathrm{b}}$ & $18.9 \pm 2.1^{\mathrm{a}, \mathrm{b}, \mathrm{d}}$ & $16.2 \pm 2.9^{\mathrm{a}, \mathrm{b}}$ & $15.5 \pm 2.25^{\mathrm{a}, \mathrm{b}, \mathrm{c}}$ \\
\hline Serum sodium, $\mathrm{mmol} / \mathrm{L}$ & $145.1 \pm 5.3$ & $191 \pm 10.5^{\mathrm{a}}$ & $153.5 \pm 13.7^{\mathrm{a}, \mathrm{b}}$ & $167.5 \pm 8.9^{\mathrm{a}, \mathrm{b}, \mathrm{d}}$ & $155.3 \pm 9.3^{\mathrm{a}, \mathrm{b}, \mathrm{c}}$ & $148.3 \pm 2.3^{\mathrm{b}, c, \mathrm{~d}}$ \\
\hline Serum potassium, $\mathrm{mmol} / \mathrm{L}$ & $4.77 \pm 0.54$ & $7.24 \pm 0.98^{\mathrm{a}}$ & $5.45 \pm 0.5^{\mathrm{b}}$ & $6.8 \pm 0.51^{\mathrm{a}, \mathrm{d}}$ & $5.65 \pm 0.66^{\mathrm{a}, \mathrm{b}, \mathrm{c}}$ & $5.15 \pm 0.54^{\mathrm{b}, \mathrm{c}}$ \\
\hline Serum IL-6, g/mL & $81.2 \pm 0.44$ & $672.2 \pm 15.6^{\mathrm{a}}$ & $256.5 \pm 13.2^{\mathrm{a}, \mathrm{b}}$ & $454.1 \pm 1233^{\mathrm{a}, \mathrm{b}, \mathrm{d}}$ & $344.8 \pm 14.7^{\mathrm{a}, \mathrm{b}, \mathrm{c}}$ & $261.2 \pm 12.34^{\mathrm{a}, \mathrm{b}, \mathrm{c}, \mathrm{d}}$ \\
\hline
\end{tabular}

Data are expressed as the means \pm SD. DN: diabetes group; FA1, FA2, FA3, and MF: diabetic rats treated with low dose (5 mg/kg) of FA (DN + FA1), middle dose $(50 \mathrm{mg} / \mathrm{kg})$ of FA (DN + FA2), high dose $(500 \mathrm{mg} / \mathrm{kg})$ of FA (DN + FA3), and (125 mg/kg) of metformin (DN + MF), respectively. Each group consisted of 10 animals.

${ }^{\mathrm{a}} P<0.05$ versus normal control group; ${ }^{\mathrm{b}} P<0.05$ versus $\mathrm{DN}$ group; ${ }^{\mathrm{c}} P<0.05$ versus $\mathrm{DN}+\mathrm{FA} 1$ group; ${ }^{\mathrm{d}} P<0.05$ versus $\mathrm{DN}+\mathrm{FA} 2$ group.

TABLE 2: Oxidant/antioxidant parameters as well as concentration of AGEs, CML, and IL-6 of rat kidney.

\begin{tabular}{|c|c|c|c|c|c|c|}
\hline & Normal control & DN & $\mathrm{DN}+\mathrm{MF}$ & $\mathrm{DN}+\mathrm{FA} 1$ & $\mathrm{DN}+\mathrm{FA} 2$ & $\mathrm{DN}+\mathrm{FA} 3$ \\
\hline SOD, $\mathrm{U} / \mathrm{mg}$ protein & $21.3 \pm 3.12$ & $8.9 \pm 2.1^{\mathrm{a}}$ & $18.25 \pm 1.55^{\mathrm{a}, \mathrm{b}, \mathrm{d}}$ & $15.5 \pm 1.8^{\mathrm{a}, \mathrm{b}, \mathrm{d}}$ & $19.93 \pm 1.4^{\mathrm{b}, \mathrm{c}}$ & $20.5 \pm 1.55^{\mathrm{b}, \mathrm{c}}$ \\
\hline $\mathrm{GSH}, \mathrm{nmol} / \mathrm{mg}$ protein & $25.6 \pm 2.12$ & $17.41 \pm 2.13^{\mathrm{a}}$ & $20.4 \pm 2.2^{\mathrm{a}, \mathrm{b}}$ & $19.85 \pm 2.19^{\mathrm{a}, \mathrm{b}}$ & $20.29 \pm 2.17^{\mathrm{a}, \mathrm{b}}$ & $23.78 \pm 1.33^{\mathrm{b}, \mathrm{c}, \mathrm{d}}$ \\
\hline $\mathrm{MDA}, \mathrm{nmol} / \mathrm{g}$ protein & $3.32 \pm 0.2$ & $7.1 \pm 0.7^{\mathrm{a}}$ & $5.1 \pm 0.35^{\mathrm{a}, \mathrm{b}, \mathrm{c}}$ & $6.2 \pm 0.21^{\mathrm{a}, \mathrm{b}, \mathrm{d}}$ & $5.05 \pm 0.5$ & $4.07 \pm 0.13^{\mathrm{b}, \mathrm{c}, \mathrm{d}}$ \\
\hline AGEs, AU & $3.4 \pm 0.2$ & $7.1 \pm 0.4^{\mathrm{a}}$ & $4.2 \pm 0.3^{\mathrm{b}, \mathrm{c}}$ & $6.2 \pm 0.35^{\mathrm{a}, \mathrm{b}, \mathrm{d}}$ & $4.85 \pm 0.55^{\mathrm{a}, \mathrm{b}, \mathrm{c}}$ & $3.9 \pm 0.6^{\mathrm{b}, \mathrm{c}}$ \\
\hline $\mathrm{CML}, \mathrm{ng} / \mathrm{mg}$ protein & $22.2 \pm 5.5$ & $48.16 \pm 6.1^{\mathrm{a}}$ & $30.5 \pm 3.5^{\mathrm{a}, \mathrm{b}, \mathrm{c}}$ & $40.8 \pm 5.4^{\mathrm{a}, \mathrm{b}, \mathrm{d}}$ & $32.3 \pm 4.8^{\mathrm{a}, \mathrm{b}, \mathrm{c}}$ & $29.5 \pm 4.1^{\mathrm{a}, \mathrm{b}, \mathrm{c}, \mathrm{d}}$ \\
\hline IL-6, ng/mg protein & $115 \pm 2.5$ & $1350 \pm 45^{\mathrm{a}}$ & $560 \pm 24^{\mathrm{a}, \mathrm{b}, \mathrm{c}, \mathrm{d}}$ & $850 \pm 35^{\mathrm{a}, \mathrm{b}, \mathrm{d}}$ & $628 \pm 31^{\mathrm{a}, \mathrm{b}, \mathrm{c}}$ & $490 \pm 28^{\mathrm{a}, \mathrm{b}, \mathrm{c}, \mathrm{d}}$ \\
\hline
\end{tabular}

Data are expressed as the means \pm SD. DN: diabetes group; FA1, FA2, FA3, and MF: diabetic rats treated with low dose (5 mg/kg) of FA (DN + FA1), middle dose $(50 \mathrm{mg} / \mathrm{kg})$ of FA (DN + FA2), high dose $(500 \mathrm{mg} / \mathrm{kg})$ of FA (DN + FA3), and (125 mg/kg) of metformin (DN + MF), respectively. Each group consisted of 10 animals.

${ }^{\mathrm{a}} P<0.05$ versus normal control group, ${ }^{\mathrm{b}} P<0.05$ versus $\mathrm{DN}$ group, ${ }^{\mathrm{c}} P<0.05$ versus $\mathrm{DN}+\mathrm{FA} 1$ group, ${ }^{\mathrm{d}} P<0.05$ versus DN + FA2 group.

levels of 8-OHdG in the DNA were markedly increased in the kidney of diabetic rats, and those increases were reversed by FA treatment $(P<0.05)$. In addition, the magnitude of these increases was reduced by FA treatment in a dose-dependent manner $(P<0.05$; Figures $1(\mathrm{a})$ and $1(\mathrm{~b}))$.

3.7. Histopathological Findings. A significant enlargement of the glomeruli, thickening of capsular basement membranes (CBMs), glomerular basement membranes (GBMs), and tubular basement membranes (TBMs), increased amounts of mesangial matrix, and tubular dilatation were observed in diabetic untreated rats (Figure 2(b)). The renal histology in untreated diabetic rats showed accelerated mesangial expansion, thickening of CBMs, GBMs, and TBMs, characterized by an increase in PAS-positive area as compared with control animals (Figures 2(a) and 2(b)). The treatment of rats with FA and MF reduced the glomerular size, thickening of CBMs, GBMs, and TBMs, increased amounts of mesangial matrix, and tubular dilatation as compared with diabetic untreated rats (Figures 2(c)-2(f)).

3.8. Effect of FA on the Acute Inflammation. In carrageenaninduced inflammatory rat models, FA at concentrations 5, 50 and $500 \mathrm{ng} / \mathrm{kg}$ inhibited the edema formation in the third hour by $38 \%(P<0.05), 42 \%$, and $57 \%(P<0.005)$ in a dose dependent manner, respectively. This effect also extended and significantly increased up to the fifth hour $(P<0.005)$. In addition, in dextran-induced inflammatory model, FA at 45 min inhibited the paw edema by $42 \%, 49 \%$, and $57 \%(P<$ 0.005 ) of inhibition at the concentrations of 5, 50 and 500 $\mathrm{ng} / \mathrm{kg}$, respectively. At $90 \mathrm{~min}$, there was an increase in the percentage of inhibition by $47 \%, 53 \%$ and $62 \%$, respectively as shown in Tables 3(a) and 3(b)

\section{Discussion}

$\mathrm{DN}$ is one of the major microvascular complications of diabetes mellitus. Hyperglycemia can lead to both a rise in reactive oxygen species (ROS) production and the attenuation of free radical scavenging compounds [36]. In the present study, the development of DN was confirmed by significant elevations of kidney/body weight ratio, Scr, sodium, potassium, and BUN as well as Upro in diabetic rats, as earlier reported by other groups $[14,15,23,28$, 37]. Oxidative stress can also affect nucleic acids resulting in modified DNA bases. 8-Hydroxy-2'-deoxyguanosine is a major product of DNA damage, and the measurement of its serum or urinary level provides information on various 


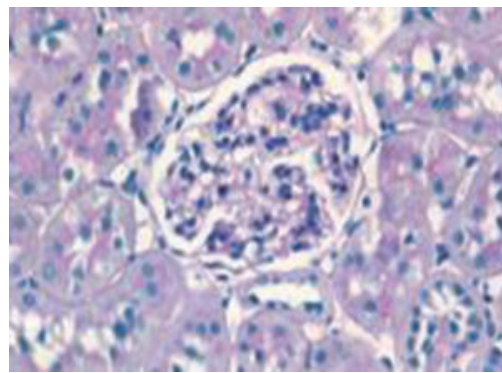

(a)

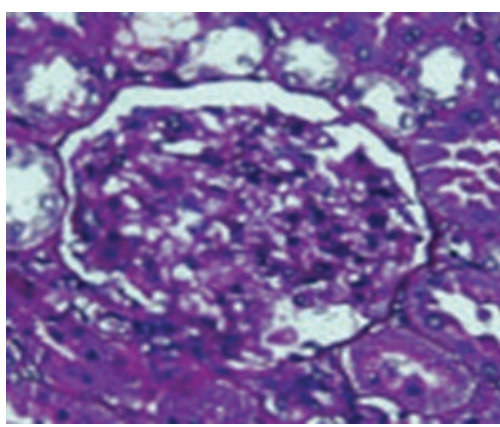

(d)

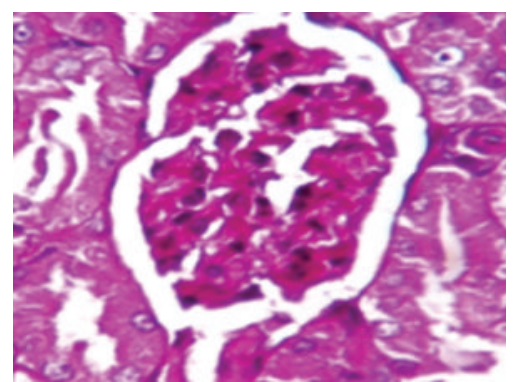

(b)

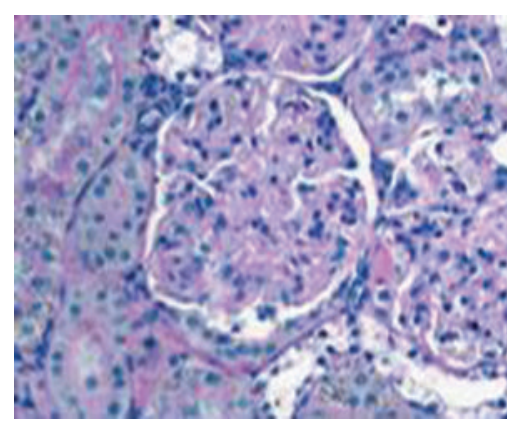

(e)

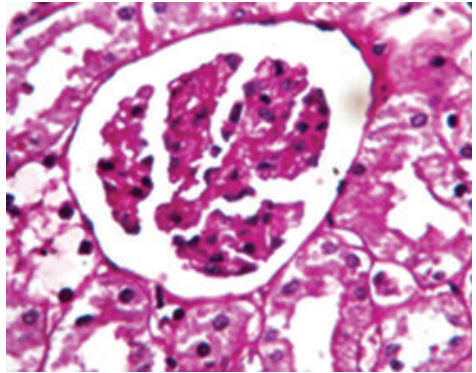

(c)

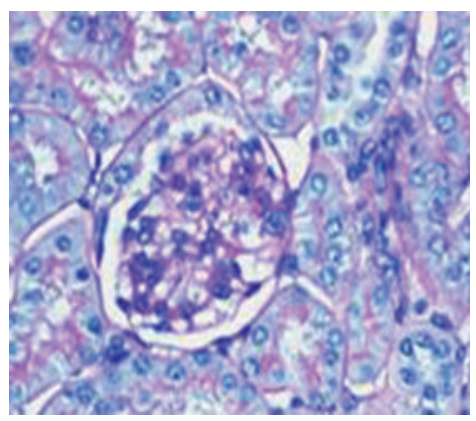

(f)

Figure 2: Figure (2): PAS staining of kidney sections of normal control rats (a), DN rats (b), DN treated with MF (c), FA1 (d), FA2 (e), and FA3 (f), respectively. Increased mesangial matrix, thickened CBMs, TBMs, and GBMs are present in the glomerulus of diabetic untreated rats as compared with the control and diabetic treated rats.

TABle 3

(a) Effect of FA on carrageenan-induced rat paw edema

\begin{tabular}{lcc}
\hline \multirow{2}{*}{ Treatment } & \multicolumn{2}{c}{ Thickness of the injected foot, $\mathrm{mm}$} \\
& $3 \mathrm{~h}$ & $5 \mathrm{~h}$ \\
\hline Olive oil & $5.1 \pm 0.12$ & $5.03 \pm 0.14$ \\
Indomethacin $10 \mathrm{mg} / \mathrm{kg}$ & $1.68 \pm 0.15(62 \%)^{* *}$ & $1.51 \pm 0.10(70 \%)^{* *}$ \\
FA, $5 \mathrm{ng} / \mathrm{kg}$ & $3.16 \pm 0.21(38 \%)^{*}$ & $3.05 \pm 0.09(39 \%)^{*}$ \\
FA, $50 \mathrm{ng} / \mathrm{kg}$ & $2.95 \pm 0.13(42 \%)^{* *}$ & $2.81 \pm 0.17(44 \%)^{* *}$ \\
FA, $500 \mathrm{ng} / \mathrm{kg}$ & $2.18 \pm 0.21(57 \%)^{* *}$ & $2.05 \pm 0.15(59 \%)^{* *}$ \\
\hline
\end{tabular}

(b) Effect of FA on dextran-induced rat paw edema

\begin{tabular}{lcc}
\hline \multirow{2}{*}{ Treatment } & \multicolumn{2}{c}{ Thickness of the injected foot, $\mathrm{mm}$} \\
& $45 \mathrm{~min}$ & $90 \mathrm{~min}$ \\
\hline Olive oil & $6.10 \pm 0.17$ & $5.90 \pm 0.17$ \\
Indomethacin, $10 \mathrm{mg} / \mathrm{kg}$ & $1.95 \pm 0.15(68 \%)^{* *}$ & $1.66 \pm 0.10(72 \%)^{* *}$ \\
FA, $5 \mathrm{ng} / \mathrm{kg}$ & $3.52 \pm 0.16(42 \%)^{*}$ & $3.1 \pm 0.09(47 \%)^{*}$ \\
FA, $50 \mathrm{ng} / \mathrm{kg}$ & $3.1 \pm 0.21(49 \%)^{* *}$ & $2.75 \pm 0.17(53 \%)^{* *}$ \\
FA, $500 \mathrm{ng} / \mathrm{kg}$ & $2.65 \pm 0.12(57 \%)^{* *}$ & $2.25 \pm 0.15(62 \%)^{* *}$ \\
\hline
\end{tabular}

Values are mean $\pm \mathrm{SE}, n=6,{ }^{*} P<0.05,{ }^{*} P<0.001$ compared with control, post-hoc test. Values given in parentheses represent percentage of inhibition.

degrees of oxidative stress at the DNA level [38]. Urinary 8OHdG excretion was significantly increased 12 weeks after the onset of diabetes. In addition, the renal cortex showed a markedly high expression of 8-OHdG in DNA. Moreover, we found for the first time that this oxidative damage is attenuated by FA treatment in a dose-dependent manner.
Furthermore, based on the obtained data, urinary and renal 8 -OHdG were significantly higher in the DN group than in the control group, which suggests that the observed renal injuries were attributed to high 8-OHdG levels in the diabetic kidney. However, FA administration prevented all the above functional and morphologic changes and maintained them 
near normal. The obtained data indicate that FA exerts its protective effects on the renal injury of diabetic rats via inhibiting the accumulation of oxidized DNA in the kidney.

Oxidative stress influences the pathogenesis of $\mathrm{DN}$ and is not only through overproduction of ROS but also through the reduction of antioxidant enzyme activities, the formation of lipid peroxides, and nonenzymatic protein glycosylation. Antioxidant enzymes are induced to protect against cellular and tissue injury. An imbalance between the production of ROS and antioxidants is believed to be involved in diabetesinduced renal failure [38]. Induction of diabetes in the present study caused a significant elevation of MDA and a reduction of both SOD activity and GSH concentration in the kidneys, as compared with the control group. Treatment with FA for 12 weeks reversed these oxidant/antioxidant parameters. The reversal of the oxidative damage due to FA is shown as a measure of antioxidant enzymes and indicates that it has possible antioxidant properties, which plays a crucial role in the defense against oxygen free radicals. The obtained data are in line with previous work $[14,15,39]$.

The hyperglycemia condition results in irreversible tissue damage by the protein glycation reaction, which leads to the formations of glycosylated proteins and AGEs [40]. AGEs accumulation in the kidney have been regarded as an index of progressive renal damage in DN. CML is formed during the metal-catalyzed oxidation of polyunsaturated fatty acids in the presence of protein [41]. Therefore, CML could serve as a general biomarker of oxidative stress resulting from carbohydrate and lipid oxidation reactions. AGEs have the ability to activate NF- $\kappa \mathrm{B}$ signaling pathway which regulate the expression of many inflammatory genes like IL-6 $[8,42]$. To test this hypothesis, we measured AGEs, CML, and IL-6 in the different groups. Actually, not only the overexpression of AGEs but also the higher levels of IL-6 in kidney of diabetic untreated rats were alleviated by 12 weeks of FA treatment. It seems that FA influenced not only the AGE-RAGE signaling but also the NF- $\kappa \mathrm{B}$-IL-6-dependent pathway to some extent, thus leading to attenuate renal damage caused by the protein glycation reaction.

To test the direct anti-inflammatory action of FA, we measured its effect on the acute inflammation induced by carrageenan and dextran on rats. FA was found to exert antiinflammatory effect which supports data obtained from the measurement of IL-6 in diabetic rats.

Controlling hyperglycemia in diabetic patients with insulin or other hypoglycemic agents and the reduction of oxidative stress, ROS production and inflammation result in the attenuation of diabetic complications especially DN. All of these findings support our hypothesis that FA has a renal protective role against oxidative damage, which may be due to its antioxidant/anti-inflammatory potential. Therefore, we accepted our hypothesis. In addition, metformin was selected as a positive control in the present study because of its well-known hypoglycemia effect. Table 1 shows that the hypoglycemic effect of all doses of FA was still lower than that of the positive drug MF. However, the high dose of FA reversed all of the renal lesions, inflammation, and oxidant/antioxidant status to almost the levels of the MF group. Therefore, our results might provide further insight into therapeutic strategies for diabetic kidney disease.

\section{Acknowledgments}

This paper was funded by the Deanship of Scientific Research (DSR), King Abdulaziz University, Jeddah, under Grant no. (34-130-D1432). The author, therefore, acknowledges with thanks DSR technical and financial support. The author wishes to acknowledge Dr. Michael Morcos, Department of Internal Medicine I (Endocrinology, Metabolism and Clinical Chemistry) Faculty of Medicine, Lüprecht-Karls University, Heidelberg, Germany, who provided ELISA kits and some fine chemicals and for his kind and continuous advice. Deep thanks go to Dr. Wafaee Gomaa, Pathology Department, Faculty of Medicine, King Abdulaziz University, KSA who did the histopathological examinations.

\section{References}

[1] D. Mahmood, B. K. Singh, and M. Akhtar, "Diabetic neuropathy: therapies on the horizon," Journal of Pharmacy and Pharmacology, vol. 61, no. 9, pp. 1137-1145, 2009.

[2] S. Shelbaya, H. Amer, S. Seddik et al., "Study of the role of interleukin-6 and highly sensitive C-reactive protein in diabetic nephropathy in type 1 diabetic patients," European Review for Medical and Pharmacological Sciences, vol. 16, no. 2, pp. 176-182, 2012.

[3] Y. S. Kanwar, J. Wada, L. Sun et al., "Diabetic nephropathy: mechanisms of renal disease progression," Experimental Biology and Medicine, vol. 233, no. 1, pp. 4-11, 2008.

[4] I.-M. Liu, T.-F. Tzeng, S.-S. Liou, and C. J. Chang, "Beneficial effect of traditional chinese medicinal formula DangguiShaoyao-San on advanced glycation end-product-mediated renal injury in streptozotocin-diabetic rats," Evidence-based Complementary and Alternative Medicine, vol. 2012, Article ID 140103, 2012.

[5] G. Giacchetti, L. A. Sechi, S. Rilli, and R. M. Carey, "The renin-angiotensin-aldosterone system, glucose metabolism and diabetes," Trends in Endocrinology and Metabolism, vol. 16, no. 3, pp. 120-126, 2005.

[6] M. Kitada, D. Koya, T. Sugimoto et al., "Translocation of glomerular $\mathrm{p} 47$ phox and $\mathrm{p} 67$ phox by protein kinase C- $\beta$ activation is required for oxidative stress in diabetic nephropathy," Diabetes, vol. 52, no. 10, pp. 2603-2614, 2003.

[7] A. A. R. Sayed and M. Morcos, "Thymoquinone decreases AGE-induced NF- $\kappa$ B activation in proximal tubular epithelial cells," Phytotherapy Research, vol. 21, no. 9, pp. 898-899, 2007.

[8] M. Morcos, A. A. R. Sayed, A. Bierhaus et al., "Activation of tubular epithelial cells in diabetic nephropathy," Diabetes, vol. 51, no. 12, pp. 3532-3544, 2002.

[9] S. Bhatia, R. Shukla, S. V. Madhu, J. K. Gambhir, and K. M. Prabhu, "Antioxidant status, lipid peroxidation and nitric oxide end products in patients of type 2 diabetes mellitus with nephropathy," Clinical Biochemistry, vol. 36, no. 7, pp. 557$562,2003$.

[10] G. G. Wang, X. H. Lu, W. Li, X. Zhao, and C. Zhang, "Protective effects of luteolin on diabetic nephropathy in STZinduced diabetic rats," Evidence-based Complementary and 
Alternative Medicine, vol. 2011, Article ID 323171, 7 pages, 2011.

[11] B. Lipinski, "Pathophysiology of oxidative stress in diabetes mellitus," Journal of Diabetes and its Complications, vol. 15, no. 4, pp. 203-210, 2001.

[12] M. Naziroğlu and M. Çay, "Protective role of intraperitoneally administered vitamin $\mathrm{E}$ and selenium on the antioxidative defense mechanisms in rats with diabetes induced by streptozotocin," Biological Trace Element Research, vol. 79, no. 2, pp. 149-159, 2001.

[13] J. J. Bhaskar, M. S. Shobha, K. Sambaiah, and P. V. Salimath, "Beneficial effects of banana (Musa sp. var. elakki bale) flower and pseudostem on hyperglycemia and advanced glycation end-products (AGEs) in streptozotocin-induced diabetic rats," Journal of Physiology and Biochemistry, vol. 67, no. 3, pp. 415425, 2011.

[14] R. Choi, B. H. Kim, J. Naowaboot et al., "Effects of ferulic acid on diabetic nephropathy in a rat model of type 2 diabetes," Experimental and Molecular Medicine, vol. 43, no. 12, pp. 676$683,2011$.

[15] A. Fujita, H. Sasaki, A. Doi et al., "Ferulic acid prevents pathological and functional abnormalities of the kidney in Otsuka Long-Evans Tokushima Fatty diabetic rats," Diabetes Research and Clinical Practice, vol. 79, no. 1, pp. 11-17, 2008.

[16] T. Nakagawa, T. Yokozawa, K. Terasawa, and K. Nakanishi, "Therapeutic usefulness of Keishi-bukuryo-gan for diabetic nephropathy," Journal of Pharmacy and Pharmacology, vol. 55, no. 2, pp. 219-227, 2003.

[17] G. Appendino, P. Spagliardi, G. Cravotto, V. Pocock, and S. Milligan, "Daucane phytoestrogens: a structure-activity study," Journal of Natural Products, vol. 65, no. 11, pp. 1612$1615,2002$.

[18] M. H. Abd El-Razek, S. Ohta, and T. Hirata, "Terpenoid coumarins of the genus Ferula," Heterocycles, vol. 60, no. 3, pp. 689-716, 2003.

[19] A. A. Ahmed, M. E. F. Hegazy, A. Zellagui et al., "Ferulsinaic acid, a sesquiterpene coumarin with a rare carbon skeleton from Ferula species," Phytochemistry, vol. 68, no. 5, pp. 680686, 2007.

[20] M. B. Aqel, S. Al-Khalil, F. Afifi, and D. Al-Eisawi, "Relaxant effects of Ferula sinaica root extract on rabbit and guinea pig smooth muscle," Journal of Ethnopharmacology, vol. 31, no. 3, pp. 373-381, 1991.

[21] M. B. Aqel, S. Al-Khalil, and F. Afifi, "Effects of a Ferula sinaica root extract on the uterine smooth muscle of rat and guinea pig," Journal of Ethnopharmacology, vol. 31, no. 3, pp. 291-297, 1991.

[22] A. A. R. Sayed, "Ferulsinaic acid attenuation of advanced glycation end products extends the lifespan of Caenorhabditis elegans," Journal of Pharmacy and Pharmacology, vol. 63, no. 3, pp. 423-428, 2011.

[23] W. Xue, J. Lei, X. Li, and R. Zhang, "Trigonella foenum graecum seed extract protects kidney function and morphology in diabetic rats via its antioxidant activity," Nutrition Research, vol. 31, no. 7, pp. 555-562, 2011.

[24] A. Troudi, I. Ben Amara, N. Soudani, A. M. Samet, and N. Zeghal, "Oxidative stress induced by gibberellic acid on kidney tissue of female rats and their progeny: biochemical and histopathological studies," Journal of Physiology and Biochemistry, vol. 67, no. 3, pp. 307-316, 2011.

[25] M. Nishikimi, N. Appaji Rao, and K. Yagi, "The occurrence of superoxide anion in the reaction of reduced phenazine methosulfate and molecular oxygen," Biochemical and Biophysical Research Communications, vol. 46, no. 2, pp. 849-854, 1972.
[26] A. A. Sayed, "Thymoquinone and proanthocyanidin attenuation of diabetic nephropathy in rats," Europian Reviews for medical and Pharmacological Science, vol. 16, no. 6, pp. 808$815,2012$.

[27] H. Ohkawa, N. Ohishi, and K. Yagi, "Assay for lipid peroxides in animal tissues by thiobarbituric acid reaction," Analytical Biochemistry, vol. 95, no. 2, pp. 351-358, 1979.

[28] R. A. Mekheimer, A. A. Sayed, and E. A. Ahmed, "Novel 1,2,4triazolo[1,5-a]pyridines and their fused ring systems attenuate oxidative stress and prolong lifespan of caenorhabiditis elegans," Journal of Medicinal Chemistry, vol. 55, no. 9, pp. 41694177, 2012.

[29] M. S. Moron, J. W. Depierre, and B. Mannervik, "Levels of glutathione, glutathione reductase and glutathione S-transferase activities in rat lung and liver," Biochimica et Biophysica Acta, vol. 582, no. 1, pp. 67-78, 1979.

[30] T. Matsubasa, T. Uchino, S. Karashima, M. Tanimura, and F. Endo, "Oxidative stress in very low birth weight infants as measured by urinary 8-OHdG," Free Radical Research, vol. 36, no. 2, pp. 189-193, 2002.

[31] H. Nakayama, T. Mitsuhashi, S. Kuwajima et al., "Immunochemical detection of advanced glycation end products in lens crystallins from streptozocin-induced diabetic rat," Diabetes, vol. 42, no. 2, pp. 345-350, 1993.

[32] A. A. Sayed, K. El-Shaieb, and A. Mourad, "Life span extension of Caenorhabditis elegans by Novel pyrido perimidine drevative," Archivs of Pharmacal Research, vol. 35, no. 1, pp. 69-76, 2012.

[33] A. Schlotterer, G. Kukudov, F. Bozorgmehr et al., "C. elegans as model for the study of high glucose-mediated life span reduction," Diabetes, vol. 58, no. 11, pp. 2450-2456, 2009.

[34] S. Fukuzawa, Y. Watanabe, D. Inaguma, and N. Hotta, "Evaluation of glomerular lesion and abnormal urinary findings in OLETF rats resulting from a long-term diabetic state," Journal of Laboratory and Clinical Medicine, vol. 128, no. 6, pp. 568578, 1996.

[35] G. Arunachalam, D. Chattopadhyay, S. Chatterjee, A. B. Mandal, T. K. Sur, and S. C. Mandal, "Evaluation of antiinflammatory activity of Alstonia macrophylla Wall ex A. DC. leaf extract," Phytomedicine, vol. 9, no. 7, pp. 632-635, 2002.

[36] J. W. Baynes, "Role of oxidative stress in development of complications in diabetes," Diabetes, vol. 40, no. 4, pp. 405412, 1991.

[37] D. Koya, K. Hayashi, M. Kitada, A. Kashiwagi, R. Kikkawa, and M. Haneda, "Effects of antioxidants in diabetes-induced oxidative stress in the glomeruli of diabetic rats," Journal of the American Society of Nephrology, vol. 14, no. 3, pp. S250-S253, 2003.

[38] K. E. Knoll, J. L. Pietrusz, and M. Liang, "Tissue-specific transcriptome responses in rats with early streptozotocininduced diabetes," Physiological Genomics, vol. 21, pp. 222229, 2005.

[39] A. A. Sayed, M. Khalifa, and F. F. Abdelatif, "Fenugreek attenuation of diabetic nephropathy in alloxan-diabetic rats," Journal of Physiology and Biochemistry, vol. 68, no. 2, pp. 263269, 2012.

[40] M. Morcos, A. Schlotterer, A. A. Sayed et al., "Rosiglitazone reduces angiotensin II and advanced glycation end productdependent sustained nuclear factor-kappaB activation in cultured human proximal tubular epithelial cells.," Hormone and Metabolic Research, vol. 40, no. 11, pp. 752-759, 2008. 
[41] M.-X. Fu, J. R. Requena, A. J. Jenkins, T. J. Lyons, J. W. Baynes, and S. R. Thorpe, "The advanced glycation end product, $\mathrm{N} \in$-(carboxymethyl)lysine, is a product of both lipid peroxidation and glycoxidation reactions," The Journal of Biological Chemistry, vol. 271, no. 17, pp. 9982-9986, 1996.

[42] A. A. R. Saved, "Thymoquinone protects renal tubular cells against tubular injury," Cell Biochemistry and Function, vol. 26, no. 3, pp. 374-380, 2008. 


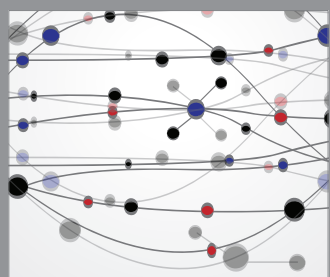

The Scientific World Journal
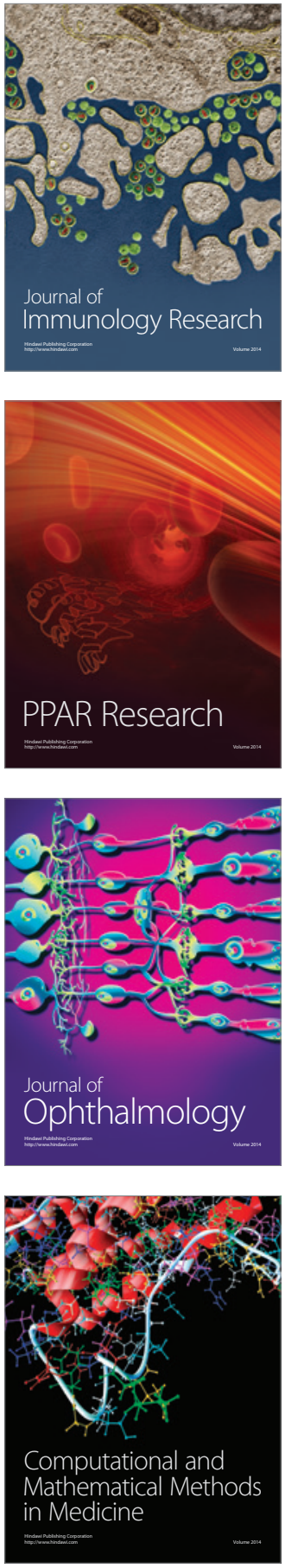

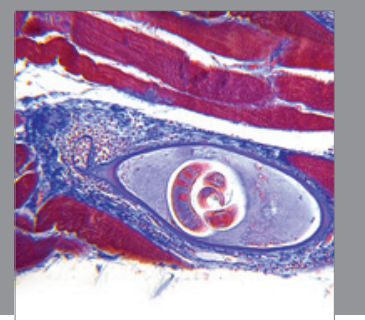

Gastroenterology

Research and Practice
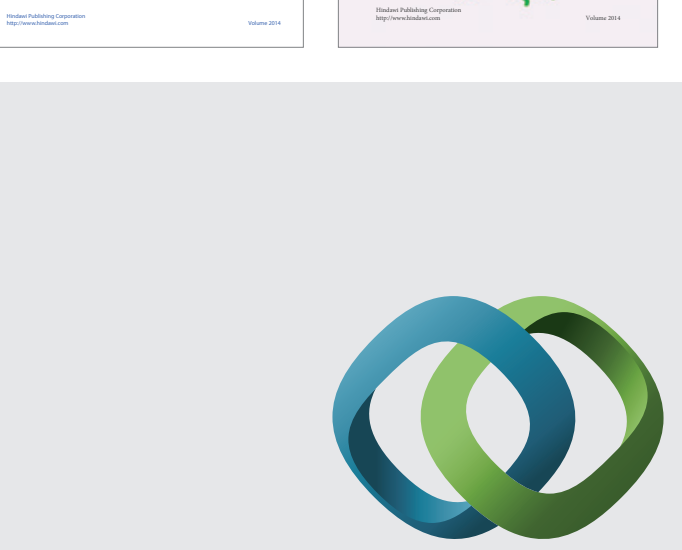

\section{Hindawi}

Submit your manuscripts at

http://www.hindawi.com
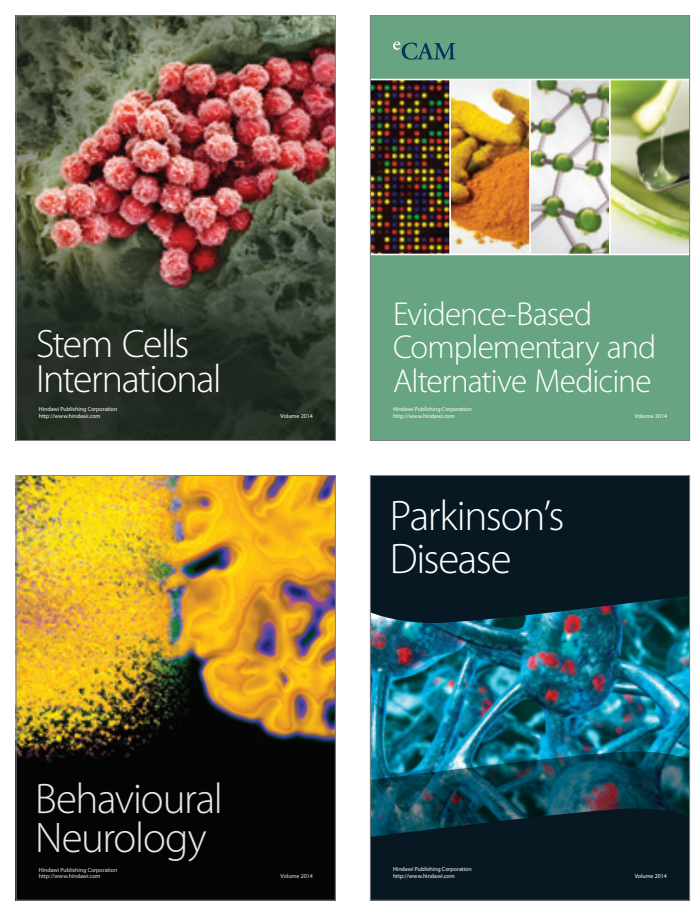

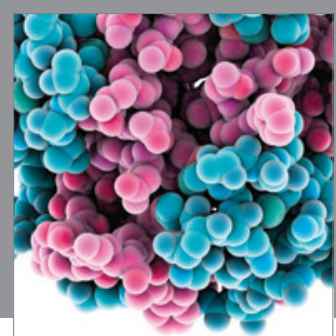

Journal of
Diabetes Research

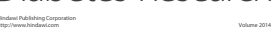

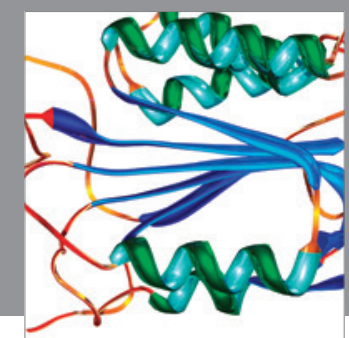

Disease Markers
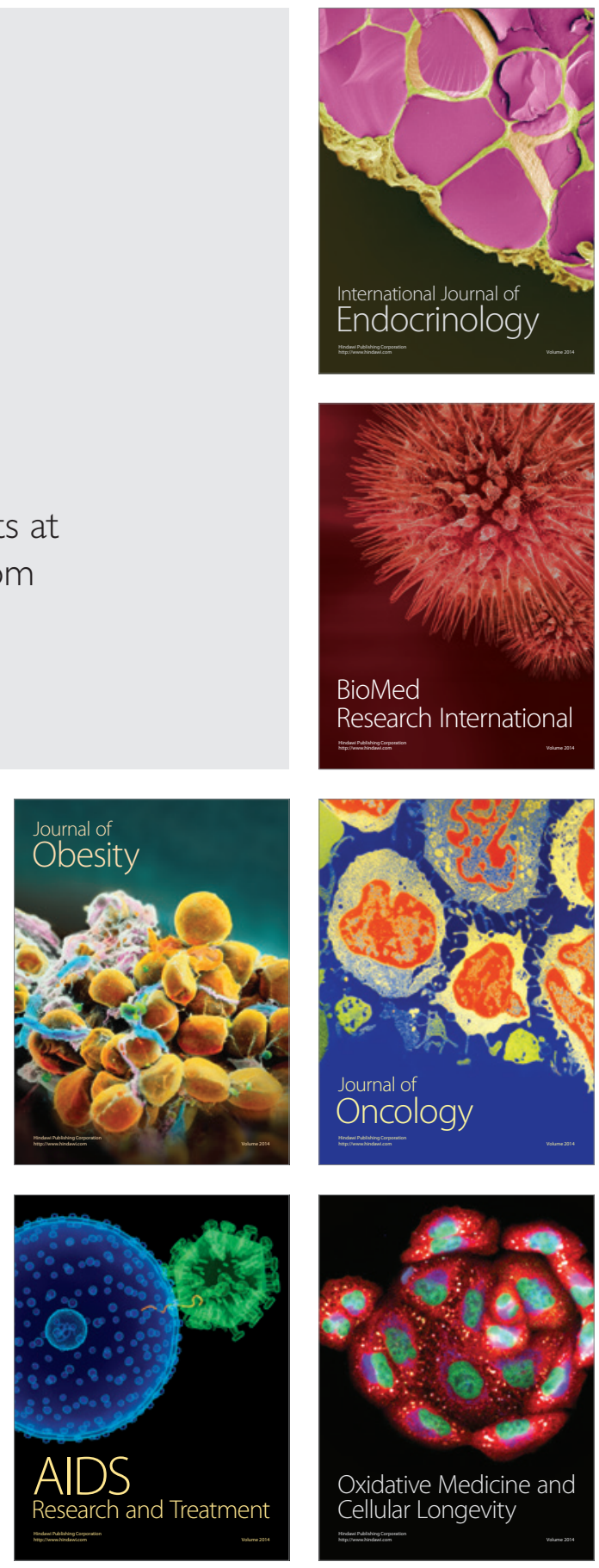